\title{
O REGISTRO DE SI E DO OUTRO: PRÁTICAS DE LEITURA E DE ESCRITA DE ESTUDANTES EM AMBIENTE DIGITAL
}

\author{
Adriana Barroso de Azevedo* \\ Lucivânia Antônia da Silva Perico ${ }^{*}$
}

\begin{abstract}
RESUMO: O presente artigo é um recorte da Dissertação de Mestrado intitulada "Ensino Médio, Língua Portuguesa e Portal Educacional: percepções emergentes das narrativas de alunos inseridos em práticas de letramento digital" (PERICO, 2015) na qual foi abordada a importância das Tecnologias Digitais de Informação e Comunicação (TDIC) no atual contexto educacional. A metodologia adotada foi a pesquisa qualitativa de cunho investigativo, na modalidade narrativa. A apuração dos dados resultou em oito categorias de análise, sendo selecionada para este artigo aquela que analisa a produção de alunos em ambiente digital. Os resultados obtidos apontaram para uma efetiva preocupação com a escrita em norma culta, por parte dos estudantes inseridos no processo, ao terem seus textos lidos, analisados e debatidos por outros colegas.
\end{abstract}

PALAVRAS-CHAVE: Tecnologias Digitais de Informação e Comunicação. Língua Portuguesa. Leitura. Escrita.

\section{Introdução}

As Tecnologias Digitais de Informação e Comunicação (TDIC) estão fortemente presentes no dia a dia das pessoas. Crianças, jovens, adultos e idosos, todos estão inseridos num cenário no qual a tecnologia tem papel cada vez mais evidente. Não sendo ela protagonista, mas, em muitos casos, mediadora do conhecimento, tornase constantemente necessária à vida das gerações no século XXI, seja pela praticidade que oferece, seja pelas possibilidades inesgotáveis de utilização.

Por sua relação estreita com o conhecimento, a tecnologia tem encontrado espaço no campo educacional. Num processo progressivo, vem participando das práticas pedagógicas de professores que desejam encontrar nela maneiras de oferecer um processo de ensino e de aprendizagem mais próximo da realidade de seu alunado,

\footnotetext{
"Universidade Metodista de São Paulo (UMESP), São Bernardo do Campo-SP, Brasil. Imeio: adriana.azevedo@metodista.br

"Universidade Metodista de São Paulo (UMESP) e Centro Paula Souza (CEETEPS), São Bernardo do Campo-SP, Brasil. Imeio: lucivania.perico@etec.sp.gov.br
} 
promovendo assim maneiras mais dinâmicas, interativas e inovadoras de aproximar o estudante do conhecimento.

Diante desse contexto, o presente artigo traz um recorte do resultado da pesquisa de Mestrado intitulada "Ensino Médio, Língua Portuguesa e Portal Educacional: percepções emergentes das narrativas de alunos inseridos em práticas de letramento digital", de autoria de Lucivânia Antônia da Silva Perico (2015), orientada pela Professora Doutora Adriana Barroso de Azevedo, defendida em fevereiro de 2015, na Universidade Metodista de São Paulo. A pesquisa foi realizada no ano de 2013, com doze alunos do $3^{\circ}$ ano do Ensino Médio de uma escola pública de São Bernardo do Campo - SP, os quais contaram com o uso de um portal educacional para complementação das aulas de Língua Portuguesa e Literatura.

A perspectiva adotada é aquela que detém o olhar nas práticas de leitura e escrita da norma culta desses alunos em ambiente online, sendo os textos desses estudantes lidos e avaliados pela professora e pelos colegas, em diversas circunstâncias de produção textual.

O objetivo deste artigo é provocar reflexões nos educadores, principalmente os de Língua Portuguesa, de tal forma que repensem suas práticas pedagógicas e seu papel no processo educativo a fim de promoverem uma experiência educativa mais condizente com a realidade dos alunos. A pesquisa, que resultou na redação deste artigo buscou investigar como práticas de ensino e de aprendizagem mediadas pelas TDIC, desenvolvidas em portal educacional, podem oferecer possibilidades de leitura e escrita na norma culta; analisar como a independência e motivação do aluno ao acessar conteúdos pode promover seu aprendizado; refletir a respeito da leitura e escrita de alunos em ambientes online, trazendo a possibilidade de quebra do paradigma de que os jovens não escrevem em norma culta na internet.

Os procedimentos metodológicos adotados foram a pesquisa qualitativa de cunho investigativo, na modalidade narrativa, caracterizada como pesquisa-ação, na 
medida em que o pesquisador estava inserido no cenário e tinha proximidade afetiva com os participantes entrevistados.

Os instrumentos investigativos selecionados para obtenção dos dados foram: entrevista semiestruturada (para promover relatos narrativos de forma espontânea); diário de bordo (que serviram como uma oportunidade de participação livre por meio do registro escrito de opiniões dos alunos a respeito das atividades desenvolvidas ao longo do ano letivo); conversas informais com os alunos (que trouxeram impressões diárias da percepção dos estudantes ao longo das atividades propostas, fazendo brotar inquietações e novos questionamentos no pesquisador); atividades realizadas no portal (que caracterizaram o aprendizado dos participantes em formação, evidenciando a trajetória formativa percorrida por meio do processo de letramento digital); caderno de pesquisa de campo (onde foram registradas as próprias expectativas do pesquisador quanto ao resultado das atividades desenvolvidas).

Após o levantamento das informações e transcrição das entrevistas, adotou-se o método de Análise Textual Discursiva, sendo a corrente teórica conhecida como escola francesa de Análise do Discurso (abreviada por AD) selecionada como mais adequada para análise dos dados apurados.

Por se tratar de um estudo de práticas pedagógicas desenvolvidas nas aulas de Língua Portuguesa, faz-se necessária uma breve reflexão a respeito do ensino da disciplina.

\section{Língua Portuguesa: entre "erros" e "acertos"}

Como afirma Bechara (2009), a diversidade da língua portuguesa permite infinitas maneiras de transmitir informações escritas e orais. O que gera também muitas discussões e até um julgamento de qual seria a forma mais adequada para se transmitir uma mensagem. Há, evidentemente, uma forma consagrada, que é a chamada norma culta. A escola é a principal responsável por transmiti-la, porém, a 
despeito dos parâmetros da gramática normativa, o falante faz suas escolhas lexicais de maneira livre e conforme lhe convém. Essas escolhas, no entanto, podem gerar um pré-julgamento do falante e por vezes resultar na sua exclusão de um determinado grupo social, é o chamado preconceito linguístico. Que pressupõe que exista uma maneira correta de dizer algo, em detrimento de outras.

A noção de "certo" e "errado", dentro da língua portuguesa, suscita debates extensos, que não são o foco deste artigo, mas que precisam ser mencionados para a compreensão de que a língua se serve à comunicação e por isso não deve existir o erro ou o acerto, o que existe é a adequação ao contexto comunicacional, porque todo texto tem um contexto e uma intenção, que determinam a escolha vocabular. Faz-se importante compreender aqui a noção de texto como "toda e qualquer forma de comunicação humana pela língua (oral ou escrita), pois tudo o que ocorre como evento comunicativo em situações sócio-culturais normais é texto." (MARCUSCHI, 2005, p.67).

No processo de disseminação da norma culta, a escola tem papel de destaque, uma vez que é o espaço de transmissão e de consagração da gramática normativa. Mas, tal papel tem sido desdobrado e, aos poucos, a escola vem repensando suas práticas, principalmente em relação ao ensino da disciplina Língua Portuguesa, responsável direta pela transmissão desse conhecimento, já que atualmente os alunos têm produzido textos nos mais diferentes suportes: e-mail, blog, redes sociais, mensagem no celular, whatsapp, dentro outros, empregando múltiplas linguagens.

Assim, chega-se ao objetivo do ensino de Língua Portuguesa neste início de século XXI, segundo o Currículo (2010, p.28): "desejamos formar para o mundo do conhecimento por meio da linguagem.", tendo em mente que

[...] os conhecimentos linguísticos não podem ser limitados apenas pelo conhecimento da norma-padrão. [...] Além disso, há o aspecto social da língua que, como organismo vivo e pulsante, transforma-se a toda hora e relaciona os textos com o momento de produção e de leitura. 
A atividade de Língua Portuguesa deve evitar que o aluno se sinta um estrangeiro ao se utilizar de sua própria língua: é necessário saber lidar com os textos nas diversas situações de interação social. [...] Assim, o centro da aula de Língua Portuguesa é o texto [...] (CURRÍCULO, 2010, p.30)

Dessa forma, não há justificativa para a oposição de muitos docentes de Língua Portuguesa e demais disciplinas ao frisarem que os alunos não têm domínio da norma culta por culpa da internet, já que, como afirma a citação acima: "os conhecimentos linguísticos não podem ser limitados apenas pelo conhecimento da norma culta". Faz-se necessário, portanto, que o estudante compreenda as diversas circunstâncias comunicacionais nas quais está inserido e adeque o seu discurso, inclusive nos ambientes online.

\section{Tecnologias digitais e o repensar da produção textual}

Dentre os diversos usos da internet por adolescente, é possível observar que é frequente a leitura e a escrita nos ambientes online: troca de e-mails, download de livros, pesquisas escolares e mensagens em grupos sociais. É perceptível a criação de uma nova prática de leitura e escrita, diferente da escolar e da impressa.

Esses gêneros digitais, por sua dinamicidade, exigem também uma nova forma de registro, o chamado "internetês". Definida por Rojo (2009, p.103) como "uma linguagem social adaptada à rapidez de escrita dos gêneros digitais em que circula bate-papo em chats, comunicação síncrona por escrito em ferramentas como MSN e blogs."

Essa modalidade de registro é alvo de críticas dos educadores que atribuem à internet (e, em particular, às redes sociais) o baixo domínio linguístico, por acreditarem que induz o jovem a escrever de maneira errônea e incentiva o desconhecimento da norma culta da língua. No entanto, é importante observar que essa nova escrita está adequada ao gênero discursivo próprio desse meio e vem reforçar a dinamicidade da língua, que permite a criação de gírias, neologismos, regionalismos etc. 
Nesta reflexão, também merece destaque um conteúdo intrigante que diz respeito à distância entre a língua falada e a língua escrita.

A fala espontânea tem como desvantagem a sua dinamicidade, de tal forma que não há muito tempo para o falante organizar o texto que pretende dizer, por isso, às vezes, a expressão das ideias pode se dar de maneira desorganizada. Uma vantagem, no entanto, é que conta com recursos como a entonação; os gestos; um contexto comum aos sujeitos; normalmente, existe a possibilidade de se solucionar dúvidas e mal entendidos no momento em que ocorrem, dentre outros.

Já a escrita pode ser planejada e, em geral, não fragmentada, apresentando-se mais completa, bem elaborada e com predominância de frases mais complexas. Sendo possível a revisão do texto, a seleção de um vocabulário mais exato e preciso. Porém, apresentando também suas desvantagens: a comunicação se faz, geralmente, na ausência de um dos participantes; não há o contexto, por isso são necessárias muitas explicações para evitar dúvidas; não se dispõe de recursos como gestos, entonação e expressões faciais.

Voltando à produção textual na internet, por conta das características do meio, há a necessidade da adaptação do texto. Como resultado, é perceptível uma escrita híbrida, uma vez que está permeada pela oralidade.

\begin{abstract}
O fato inconteste é que a Internet e todos os gêneros a ela ligados são eventos textuais fundamentalmente baseados na escrita. Na Internet, a escrita continua essencial apesar da integração de imagens e som. Por outro lado, a ideia que hoje prolifera quanto a haver uma "fala por escrito" deve ser vista com cautela, pois o que se nota é um hibridismo mais acentuado, algo nunca visto antes [...] (MARCHUSCHI, 2005, p.19)
\end{abstract}

Também é importante destacar que o uso constante de abreviações faz com que surjam termos que atendem à necessidade do falante naquele momento de escrita, mas que podem ter seu uso consagrado, criando-se assim um cânone, o que significa asseverar a contribuição dessa escrita para a formação de novas variedades comunicativas, tal como ocorre na fala. 
A polêmica que se gera em cima do uso do "internetês" vem da posição de alguns professores que não compreendem a relevante função do ensino de Língua Portuguesa quando se considera a questão do seu papel social. O estudante precisa conhecer sim a norma culta, é dever da escola ensiná-la, mas o professor também precisa fornecer ao aluno subsídios para que possa comunicar-se em qualquer situação: "a grande missão do professor de língua materna (...) é transformar seu aluno num poliglota dentro de sua própria língua, possibilitando-Ihe escolher a língua funcional adequada a cada momento de criação". (BECHARA, 2007, p. 14). Portanto, estabelece-se um grande desafio.

É importante considerar, como preconizam Fiorin e Savioli (2007, p.221), que "usar a linguagem adequada a cada situação é uma das qualidades do bom usuário do idioma", por isso a escola precisa ensinar os gêneros e propiciar ao aluno a compreensão de quais são os contextos de utilização desses textos. Mas também deve ensinar que "não se pode afirmar que exista um padrão de linguagem superior em termos absolutos: a situação concreta de comunicação é que determina a forma de linguagem mais ou menos eficiente" (FIORIN e SAVIOLI, 2007, p.221), portanto, não é possível dizer que o "internetês" seja errado, mas é possível orientar que, por exemplo, na produção de uma dissertação para um vestibular, o emprego dessa modalidade de escrita será inadequado.

O que não se pode perder de vista é o caráter histórico e cultural da língua.

\begin{abstract}
Todo texto assimila as ideias da sociedade e da época em que foi produzido. [...] Quando se afirma que os textos se relacionam com a história, não se quer dizer que eles narram fatos históricos de um país, mas que revelam os ideais, as concepções, os anseios e os temores de um povo numa determinada época. [...] As ideias de uma época estão presentes nos significados dos textos. (FIORIN e SAVIOLI, 2007, p.27)
\end{abstract}

Em pleno século XXI, negligenciar as produções textuais dos jovens na internet é tentar apagar parte da história e da cultura que se está escrevendo. O que hoje pode parecer mero entretenimento, amanhã servirá como material para estudos 
linguísticos, históricos, culturais e sociais, em muitos casos, até literários, uma vez que é grande a produção de crônicas, contos, poemas etc. em blogs, sites e nas redes sociais.

\title{
A escola enquanto espaço incentivador de letramentos
}

A escola, tendo a consciência de que seus alunos vivem numa sociedade letrada na qual tanto os sujeitos escolarizados como os não-escolarizados estão inseridos, deve assumir a postura favorável ao ensino dos letramentos. Esses letramentos devem ser entendidos como "capacidades de leitura", nas palavras de Rojo (2009, p.27), que envolvem aspectos culturais e sociológicos.

Em consonância com toda essa reflexão e para amalgamar os pontos levantados, o conceito de "letramento digital" faz-se oportuno. Segundo Coscarelli (2005, p.9), "é o nome que damos, então, à ampliação do leque de possibilidades de contato com a escrita também em ambiente digital (tanto para ler quanto para escrever)". Utilizar o termo "letramento digital" faz recobrar a necessidade de se inserir as Tecnologias Digitais de Informação e Comunicação (TDIC) na Educação.

Outro ponto relevante está nas práticas:

\begin{abstract}
Creio não estar errado em afirmar que cabe à escola e ao professor organizar e implementar práticas de leitura / escrita que leve os estudantes ao domínio de competências para o manejo dos dois tipos de textualidade (impressa e digital), mesmo porque há vantagens e desvantagens em ambas, além de usos sociais próprios de cada uma delas. Outrossim, sabendo que a frequência a esses dois mundos multiplicará exponencialmente a exposição dos estudantes a uma grande variedade de textos, caberá aos professores estabelecer critérios de busca e seletividade de modo a, inclusive, gerar significação para as buscas e pesquisas através da leitura. (SILVA, 2003, p. 123)
\end{abstract}

É fundamental que a escola tenha em mente que suas práticas devem ser condizentes com a realidade e as necessidades de seu alunado. Para isso, o ensino (não apenas de Língua Portuguesa, mas de todas as disciplinas) tem por dever garantir que os estudantes sejam capazes de desenvolver as diferentes formas de 
uso das linguagens (verbal, musical, gráfica etc.) e das línguas (variedades linguísticas) para poderem participar das práticas cidadãs e profissionais, em ambiente presencial ou virtual. Para isso, é necessário que os alunos desenvolvam as competências básicas que lhes darão plena autonomia para lidar com as línguas, as linguagens, as mídias e as múltiplas práticas letradas de maneira ética, crítica e protagonista.

Diante da reflexão acima e de práticas de leitura e escrita em ambiente digital por alunos do $3^{\circ}$ ano do Ensino Médio, incentivadas e desenvolvidas nas aulas de Língua Portuguesa, numa escola pública de São Bernardo do Campo, pôde-se elaborar o breve estudo que se segue:

\section{Apresentação e discussão dos resultados}

Para se compreender o cenário: os estudantes contavam com um portal educacional para suporte das aulas de todas as disciplinas. Com o propósito de promover o letramento digital de seus alunos, a professora da disciplina Língua Portuguesa propôs atividades diversas no portal. O interesse dos alunos, sua motivação para realizar as atividades e a melhoria de seu desempenho nas aulas presenciais despertou a atenção da professora, que se dispôs a pesquisar as percepções desses jovens a respeito do processo de aprendizagem mediado pela tecnologia digital, resultando na Dissertação de Mestrado, da qual se faz este pequeno recorte, em formato de artigo.

A análise dos dados levantados permitiu a elaboração de oito categorias emergentes das narrativas dos participantes: interação e comunicação; sala de aula ampliada; gestão da aprendizagem; o registro de si e do outro; aprendizagem colaborativa e transformadora; incentivo à pesquisa; estudo autônomo; e, desafios. Neste artigo, analisa-se a categoria "o registro de si e do outro", na medida em que reflete-se a respeito das produções textuais de alunos em meio digital. 
A categoria "O registro de si e do outro" busca, de certa forma, desmistificando a ideia de que o jovem na internet não utiliza a norma culta, mas somente o "internetês", mostrando que é possível ao professor de Língua Portuguesa fazer do aluno um "poliglota dentro de sua própria língua", como propôs Evanildo Bechara (2007).

Uma das propostas do Currículo do Estado de São Paulo para o ensino de Língua Portuguesa é o conhecimento da norma culta para a produção dos gêneros discursivos, bem como a primeira das cinco competências da redação do Enem é demonstrar domínio da norma culta, observando esses aspectos, o redigir na internet, dentro da proposta de ensino e de aprendizagem atual, deve contemplar o desenvolvimento dessas competências.

Para motivar o aluno, foi adotada como melhor escolha expô-lo a situações de aprendizagem em que tivesse que posicionar-se, expressar por escrito sua opinião, argumentar com os colegas e com a professora. Uma das atividades que mais chamou a atenção dos participantes foi o debate no 'Blog do Professor', a proposta mesclou o debate, gênero textual próprio da oralidade, com o blog, recurso que requer a produção de um gênero textual escrito. Essa mescla rendeu muitos frutos, pois os alunos jamais tinham participado de um debate escrito, o que possibilitou a participação de todos que desejassem, inclusive os mais tímidos, que em sala, provavelmente, permaneceriam calados, também incentivou os envolvidos a pesquisarem e redigirem com qualidade o seu texto.

A respeito dessa prática, assim se manifestou $\mathrm{E} 1$ ao ser questionado como se sentia quando tinha sua opinião lida por outros colegas: Me sinto muito bem porque eu passo meu texto para as pessoas lerem e tenho orgulho da minha opinião. E2 tem a mesma postura em relação aos textos que redige: (...) eu quero que as pessoas leiam o meu texto, eu quero saber a opinião delas, que nem no 'Blog do Professor', debater sobre isso, então eu gosto que as pessoas leiam meu texto e digam a opinião delas sobre isso. 
E7, ao ser questionado se o incomodava ter seu texto lido, reforçou: Não, porque eu acho que por mais que as pessoas venham a discordar da minha opinião, por mais que ela pareça boba, na vida tem que opinar sobre as coisas, sempre as pessoas estão sempre julgando. Eu não me importo. O aluno $\mathrm{E} 9$, também em resposta à questão anterior diz: Não. Eu gosto que eu vejo se as pessoas gostaram ou não, também. Então, eu gosto pra caramba e dá pra me impor, eu gosto disso.

Porém, não foram todos os casos em que o estudante se sentiu confortável ao saber que os colegas leriam o seu texto: Eu não gosto que os outros analisem o meu texto. Eu acho que eu fico um pouco com vergonha. Mas a ferramenta é boa porque eu leio o dos outros, assim, pra ter uma noção de como está o meu texto, mas é um pouco... Eu não gosto muito.(E4). Dois pontos são interessantes e sobressaem desse discurso: o aprendizado que ocorre por meio do contato com o texto do outro e o que o texto traz a respeito de quem o redige.

O texto do outro pode ensinar muito, pode ser um balizador do próprio texto de quem redige, a partir do momento em que pode compará-lo. Em relação à necessidade de refletir a respeito de sua linguagem, considerando a leitura do texto do colega, assim se pronunciou E8:

(...) na hora que você coloca seus conhecimentos em prática, você realmente tende a aprimorar, você observa seus erros, você observa o ponto em que você precisa melhorar, observa obviamente o esforço que você teve, etc... mas comparando com os outros você vendo o nível de desenvolvimento de linguagem dos outros com o seu, você percebe o quanto você precisa melhorar e o quanto você precisa se esforçar para atingir esse melhor. Eu acho que auxiliou bastante nesse ponto de linguagem, também foi bastante importante para comparar não só o ponto de vista etc... mas uso de recursos e seleção, etc. de figuras de linguagem etc. para formular uma, para colocar o que você quer dentro do texto, então foi realmente útil na hora.(...) quando me é possibilitado ver o texto do outro, eu uso para ver como deve ser o nível de discussão, e também para ver se já obtiveram vários outros resultados, para ver diversos pontos de vista qual seria melhor aguardar, se eu devo aguardar tudo de uma vez, se eu devo especificar em um só, então eu utilizo os textos, não só na 'Escrita Coletiva', mas também no 'Blog do Professor', ou em outras ferramenta de produção de texto para ter, quando me é disponibilizado, para ter uma noção, uma base de como deve ser feito. 
E seguiu, trazendo à tona a preocupação com a escrita: Eu procuro me policiar um pouco mais sabendo que várias outras pessoas vão ler, mas eu não vou deixar de emitir minha opinião, o que eu penso sobre tal assunto por outras pessoas estarem lendo, mas eu procuro me policiar um pouco mais.(E8). Preocupação essa demonstrada no discurso de outros colegas:

(...) o 'Redator de Jornal' também foi uma experiência muito legal. A gente fazer foi, hum... Eu não queria fazer um jornal assim de qualquer jeito, sabe? Eu queria que o jornal ficasse impecável, incrível, então a gente pesquisou muito, a gente elaborou vários textos, a gente foi vendo qual texto tinha ficado mais legal, então acho que essas ferramentas que a gente mostra alguma coisa para outras pessoas é o que mais instiga a gente a mostrar. (...) Olha, quando eu posto alguma coisa minha é que eu gosto muito de dar minha opinião, né, e aí quando eu posto alguma coisa minha eu presto muita atenção na ortografia e na gramática porque eu morro de medo de fazer feio, então eu pesquisei bastante antes de falar alguma coisa e eu redigi o texto várias vezes, passei no Word para correção ortográfica. Olhei tudo (...) sempre gostei de ler, e todos os meios literários: blogs, tudo, tudo, eu gosto de ler tudo, anúncio, tudo, classificados, e eu tinha essa preocupação de estar com a ortografia sempre bem colocada, porque é uma impressão que a gente passa, né... a pessoa vai lá e lê e às vezes tem uns erros tão absurdos que a pessoa já faz uma cara feia para o seu texto, logo no começo. Assim, vi um erro, já vi o seu texto de outro jeito, como se você não tivesse propriedade no que você está falando por causa do seu erro gramatical, então eu procuro sempre ter cuidado com isso.(...) Eu acho, eu acho que dá outra visão de sua opinião que as pessoas falam: "Ah! Não sabe nem escrever, vai saber do que está falando!". (E12)

Essas duas falas, foram reforçadas por E7:

(...) você tem a internet pra pesquisar, então você acaba sempre pesquisando um pouco mais pro assunto que você tem que pra escrever e você tenta escrever o mais certo possível porque você sabe que mais pessoas vão ler aquilo e vão falar: "Nossa! Ela não sabe escrever."(...) Isso [saber que os outros lerão o seu texto] é bom porque quando você escreve só pro professor olhar, mas é só ele que vai olhar, e você também não pode pesquisar em nenhum outro lugar, vai ser o que você sabe, o que acaba ficando um pouco fraco, agora, na internet, você acaba pesquisando, você acaba aprendendo, sabe aquilo e até sobre outras matérias e você tem que escrever o mais certo possível, porque exatamente pra não ter aquela coisa do amiguinho vir e falar...

Tais relatos são uma grande fonte de reflexão para os professores, pois demonstram que quando orientado, quando consciente daquilo que será avaliado, considerando que seja também o domínio da norma culta, o aluno pode ter grande preocupação 
com o registro. E sabedor de que se trata de uma situação formal de comunicação, ele terá mais cuidado, pois não trata-se apenas de ser avaliado pelo professor, mas de ser avaliado pelo colega. Ser avaliado e julgado por aquilo que escreve. É o que o texto traz a respeito de quem o redige!

Nessa toada, o argumento de que a internet tem prejudicado a escrita dos jovens cai por terra. Quando o estudante usa o "internetês", ele o faz para pertencer a um grupo, é esse o objetivo, mas ele também pode e deve fazer uso da norma culta na sua escrita na internet, desde que esse seja o critério para que ele pertença ao grupo. Dessa forma, cabe ao professor direcionar o aluno para adequar o seu discurso ao contexto no qual estará inserido, trata-se, portanto, de adequação linguística.

Segundo Sartori (2014, p. 76), "a linguagem usada na publicação de mensagens nos blogs em geral não são informais, espontâneas, sem revisão" e reitera: "Pelo contrário, trata-se de um texto promocional, muito bem formatado, que cumpre a expectativa de divulgação, de publicação, pois mesmo que seja um blog de caráter privado outras pessoas irão lê-lo." (PRIMO, 2008, p.124 apud SARTORI, 2014, p.76), portanto, afirmar que a internet prejudica a escrita dos alunos é ignorar que quando ele emprega o "internetês" ou a norma culta em cada situação específica de comunicação ele está sendo "poliglota", está inserido numa prática de letramento digital em que tem domínio suficiente da linguagem para utilizá-la de acordo com as suas intenções, dentro de um dado contexto, considerando o seu interlocutor.

Vale ressaltar o quanto as novas tecnologias digitais vêm influenciando a nossa sociedade, "com as novas tecnologias digitais, vem-se dando uma espécie de 'radicalização do uso da escrita' e nossa sociedade parece tornar-se 'textualizada', isto é, passar para o plano da escrita." (MARCUSCHI, 2005, p.15), assim, os gêneros textuais têm ocupado espaço como fenômeno social, histórico e cultural, numa comunicação escrita mediada por computador, desenvolvendo um discurso presente em gêneros emergentes no meio virtual como e-mail, chat, blog, diário de bordo, dentre outros. 
Considerar aspectos da escrita pressupõe considerar também a leitura. O registro de si e do outro requer a leitura de si e do outro. Como assegura Chartier (1998, p.77):

\begin{abstract}
A leitura é sempre apropriação, invenção, produção de significados (...), o leitor é um caçador que percorre terras alheias. Apreendido pela leitura, o texto não tem de modo algum - ou ao menos totalmente - o sentido que lhe atribui seu autor, seu editor ou seus comentadores. Toda história da leitura supõe, em seu princípio, esta liberdade do leitor que desloca e subverte aquilo que o livro the pretende impor. Mas esta liberdade leitora não é jamais absoluta. Ela é cercada por limitações derivadas das capacidades, convenções e hábitos que caracterizam, em suas diferenças, as práticas de leitura. Os gestos mudam segundo os tempos e lugares, os objetos lidos e as razões de ler. Novas atitudes são inventadas, outras se extinguem. Do rolo antigo ao códex, do livro impresso ao texto eletrônico, várias rupturas maiores dividem a longa história das maneiras de ler. Elas colocam em jogo a relação entre o corpo e o livro, os próprios usos da escrita e as categorias intelectuais que asseguram sua compreensão.
\end{abstract}

Ao longo do tempo, o leitor reconfigurou a sua relação com o objeto de ler (pergaminho, papiro, livro, tela) e observou características do velho texto no novo suporte, o que exigiu dele certa adaptação. Estranhamento igual é possível observar hoje com a proposta de leitura na tela. "O leitor se adapta ao novo suporte, ao novo objeto de ler, e o novo objeto vai sendo refinado e projetado de acordo com as demandas do leitor, fundamentadas no uso. Trata-se, então, de um ciclo inteligente e versátil, ao qual qualquer ser humano deve estar acostumado." (RIBEIRO, 2005, p.130). Assim, o leitor tem a possibilidade de ter dois aprendizados: a mensagem que o texto traz e o aprendizado do manuseio do suporte.

Ribeiro (2005, p.134) destaca: "Os gêneros de texto existem em consonância com seus suportes", isto posto, observa-se que a relação suporte-gênero textual é próxima, uma vez que há gêneros que surgiram juntamente com seu suporte, o email é um bom exemplo.

Retomando a reflexão a respeito da leitura, para Santos (2005, p. 152) "o adolescente está em permanente contato com a leitura, tendo acesso, diariamente, a inúmeros gêneros de textos", ao que destaca panfletos, revistas, out doors, cartazes, dentre outros, incluindo ainda blogs, sites, chats e esse contato com a 
leitura e a escrita na sociedade letrada em que vivemos faz com que exista uma exigência de adaptação ao momento e ao gênero para que o jovem possa comunicar-se e pertencer a um grupo social.

Assim, ao longo deste estudo, foi possível observar como os participantes perceberam a importância da linguagem escrita em suas práticas online de comunicação e o impacto dela no julgamento que os outros fazem deles e eles fazem dos outros.

Para concisão dos resultados apresentados e discutidos, segundo os procedimentos metodológicos adotados, elaborou-se o mapa conceitual abaixo:

Fig. 1 - O registro de si e do outro (PERICO, 2015, p.119)

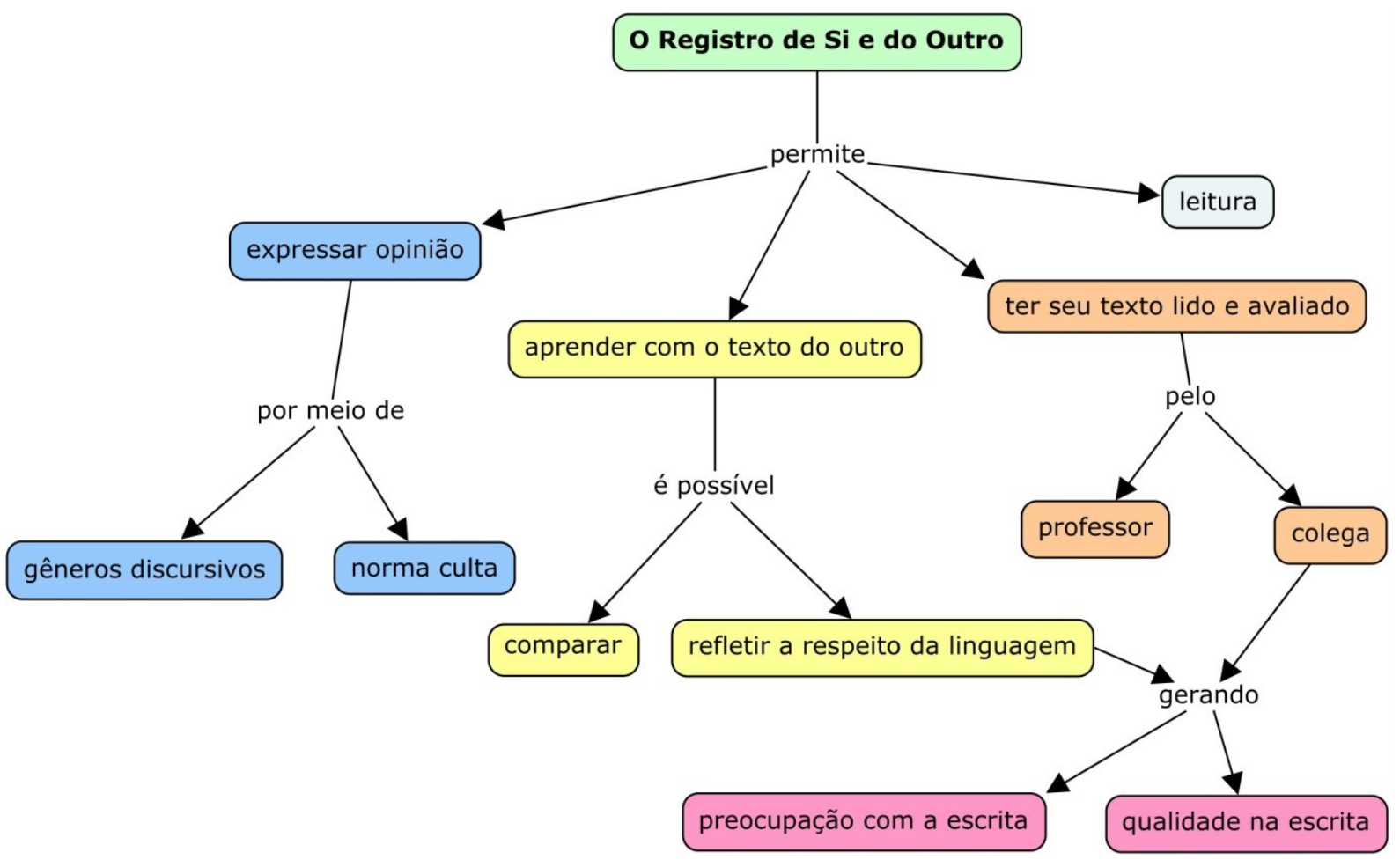

\section{Considerações finais}

$\mathrm{Na}$ intenção de costurar os recortes feitos acima num todo significativo, torna-se relevante considerar: 
Primeiro: a visão de que apenas o domínio da norma culta é suficiente para a aquisição dos conhecimentos linguísticos necessários à comunicação vem aos poucos decaindo. Dando lugar, sobretudo, à compreensão da importância do domínio da norma culta e da sua utilização de acordo com o contexto comunicacional. Abandonando-se, dessa forma, a noção de "acerto" e "erro", adotando-se a "adequação linguística".

Segundo: a língua, considerando os fatores que levam à variação, requer dos sujeitos envolvidos na comunicação um conhecimento mais que gramatical. Ela deve ser reconhecida também no que concerne ao seu aspecto social, como espaço de "intercomunicação social", como afirmou Bechara (2009, p.28), uma vez que "a linguagem é sempre um estar no mundo com os outros" e o viver em sociedade, pressupõe exercício de cidadania; e para exercer esse papel, o estudante de Língua Portuguesa também deve estar preparado.

Terceiro: o ensino deve conferir ao aluno a habilidade de utilizar a sua língua; e a concretização da língua se dá na produção do texto, seja ele oral ou escrito. Assim, torna-se imprescindível que o aluno seja capaz de produzir e compreender os diversos textos com os quais tem contato cotidianamente e, para que os sujeitos envolvidos no processo comunicacional comuniquem e compreendam os textos, fazse fundamental o conhecimento dos gêneros textuais ou gêneros discursivos, assim denominados por Bakhtin (2000).

Para tanto, não é necessária uma revolução complexa, basta uma revisão dos programas de ensino de tal forma que passem a contemplar os gêneros textuais das diversas esferas de atividade social. Cabe também apontar que as escolhas do professor devem ser condizentes com os objetivos de aprendizagem. Diante desses princípios norteadores será possível selecionar aquilo que é "ensinável" e importante de ser aprendido, tendo em mente que essas escolhas viabilizam aos alunos situações de produção, aprendizagem e protagonismo e também dão protagonismo ao professor. Todos ganham! 


\title{
THE RECORD OF ONESELF AND THE OTHERS: READING AND WRITING PRACTICES OF STUDENTS IN DIGITAL ENVIRONMENT
}

\begin{abstract}
This article is an excerpt of the Master's thesis entitled "High School, Portuguese Discipline and Educational Portal: emerging perceptions of the narratives of students entered in digital literacy practices" (PERICO, 2015) in which was discussed the importance of Digital Information and Communication Technologies (DICT) in the current educational context. The adopted methodology was the qualitative research of investigative nature, in narrative form. The investigation of the data resulted in eight categories of analysis, being selected for this article the one that analyzes the production of students in the digital environment. The results pointed to a real concern with writing in standard Portuguese rules, by the students included in the process, to have their texts read, analyzed and discussed by other colleagues.
\end{abstract}

KEYWORDS: Digital Information and Communication Technologies. Portuguese Language. Reading. Writing.

\section{Referências bibliográficas}

BAKHTIN, M. Os gêneros do discurso. In: M. Bakhtin. A estética da criação verbal. $3^{a}$ Edição. São Paulo: Martins Fontes, p.277-326, 2000.

BECHARA, Evanildo. Ensino da Gramática: Opressão? Liberdade? São Paulo: Ática, 2007.

2009.

Moderna Gramática Portuguesa. 37. ed. Rio de Janeiro: Nova Fronteira,

CHARTIER, Roger. A aventura do livro: do leitor ao navegador. Tradução de Reginaldo Carmello Corrêa de Moraes. São Paulo: Editora UNESP, 1998.

COSCARELLI, Carla Viana. Alfabetização e letramento digital. In: COSCARELLI, Carla. RIBEIRO, Ana Elisa (Org.). Letramento Digital: aspectos sociais e possibilidades pedagógicas. Belo Horizonte: Ceale; Autêntica, 2005.

FIORIN, José Luiz; SAVIOLI, Francisco Platão. Para entender o texto: leitura e redação. 17. ed. São Paulo: Ática, 2007.

MARCUSCHI, Luiz Antônio; XAVIER, Antônio Carlos (Orgs.). Hipertexto e gêneros digitais: novas formas de construção do sentido. 2. ed. Rio de Janeiro: Lucerna, 2005.

PERICO, Lucivânia A. Silva. Ensino Médio, Língua Portuguesa e Portal

Educacional: percepções emergentes das narrativas de alunos inseridos em práticas de letramento digital. 2015. 227 f. Dissertação (Mestrado em Educação) Faculdade de Humanidades e Direito, Universidade Metodista de São Paulo. 
RIBEIRO, Ana Elisa. Ler na tela - letramento e novos suportes de leitura e escrita. In: Letramento Digital: aspectos sociais e possibilidades pedagógicas.

Belo Horizonte: Ceale; Autêntica, 2005.

ROJO, Roxane. Letramentos múltiplos, escola e inclusão social. São Paulo: Parábola Editorial, 2009. (Série Estratégias de Ensino 13).

SANTOS, Else Martins dos. Chat: e agor@? Novas regras - nova escrita. In: Letramento Digital: aspectos sociais e possibilidades pedagógicas. Belo Horizonte: Ceale; Autêntica, 2005.

SÃO PAULO (Estado) Secretaria da Educação. Currículo do Estado de São Paulo: Linguagens, códigos e suas tecnologias. Secretaria da Educação; coordenação geral, Maria Inês Fini; coordenação de área, Alice Vieira. São Paulo: SEE, 2010.

SARTORI, Ademilde Silveira (Org.). Educomunicação e a criação de ecossistemas comunicativos: diálogos sem fronteiras. 1. ed. Florianópolis: DIOESC, 2014.

SILVA, Ezequiel Theodoro da. Formação do leitor virtual pela escola brasileira: uma navegação por mares bravios. In: FREIRE, Fernanda M. P.; ALMEIDA, Rubens Q. de; AMARAL, Sérgio Ferreira do; SILVA, Ezequiel Theodoro da. (Coord.);. A leitura nos oceanos da internet. São Paulo: Cortez, 2003.

Texto recebido em: 30/04/2015.

Texto aceito em: 24/07/2015. 